\title{
MARXISMO Y PSICOANÁLISIS: UNA RESPUESTA A MANUEL MARTÍNEZ
}

\section{MARXISM AND PSYCHOANALYSIS. A RESPONSE TO MANUEL MARTÍNEZ}

\author{
Roy Alfaro Vargas*
}

\begin{abstract}
É na constituição dos grupos que se vê melhor a eficácia das representações, e em particular das palavras, das palavras de ordem, das teorias que contribuem a fazer a ordem social impondo os princípios de divisão e o poder simbólico de todo o teatro político que realiza e oficializa as visões de mundo e as divisões políticas.
\end{abstract}

José Sergio Leite Lopes

RESUMEN

Este artículo es una respuesta a la propuesta de Manuel Martínez. Aquí se analiza críticamente el planteamiento de él con respecto a la relación entre psicoanálisis y marxismo. Se plantean algunas de las fallas del enfoque martineziano, con el fin de acceder a una mejor comprensión de los elementos que unen ambos paradigmas teóricos. Finalmente, se analiza el concepto de autoestima, en tanto nuevo objeto psicoanalítico.

PALABRAS CLAVE: POSMODERNIDAD * MARXISMO * PSICOANÁLISIS * SUJETO * AUTOESTIMA

\section{ABSTRACT}

This article analyzes the relationship between Marxism and Psychoanalysis around the Manuel Martinez proposal, where he pretends to find an incompatibility between both paradigms. Then, I point out some mistakes linked to the Martinez proposal. Also, I analyze some quotidian examples that permit to grasp better the theoretical relation between both approaches. Finally, I suggest the self-esteem concept as the new epistemological object of Psychoanalysis.

\section{KEYWORDS: POSTMODERNITY * MARXISM * PSYCHOANALYSIS * SUBJECT * SELF-ESTEEM}




\section{INTRODUCCIÓN}

La idea de este artículo nace de la propuesta que hace Manuel Martínez (2007) titulada "Psicoanálisis y Marxismo: una imposibilidad paradigmática". En él, Martínez plantea sus consideraciones al respecto de la relación psicoanálisis-marxismo (las cuales explicaremos más adelante). Nuestro interés es profundizar en los lazos que unen estas dos teorías, para lo cual plantearemos la siguiente tesis: la posibilidad de amalgamar ambas propuestas teóricas implicará necesariamente una aproximación dialéctica, en la cual el concepto de autoestima sirva de síntesis entre el sujeto del psicoanálisis $y$ el del marxismo, en tanto nuevo espacio epistemológico que une ambos paradigmas.

Nuestro principal interés es continuar con el espacio de discusión, abierto por Martínez, en relación con la posibilidad de amalgamar estos dos paradigmas.

Para alcanzar exitosamente nuestra tesis, es preciso cumplir con los siguientes objetivos:

1. Elaborar un resumen del enfoque de Martínez al respecto de la relación marxismo-psicoanálisis.

2. Señalar críticamente los fallos del enfoque martineziano en relación con el marxismo y el psicoanálisis.

3. Definir el concepto de autoestima, como espacio sintético de la relación antitética entre marxismo y psicoanálisis, en tanto nuevo eje epistemológico de cohesión entre ambos paradigmas.

\section{LA RELACIÓN PSICOANÁLISIS-MARXISMO EN MANUEL MARTÍNEZ}

Martínez (2007) intenta mostrar la incompatibilidad de los paradigmas teóricos marxista y psicoanalítico. Desde un inicio, el texto es engañoso, ya que, las palabras psicoanálisis y marxismo parecen remitir al psicoanálisis en general $y$, de igual modo, al marxismo. No obstante, él refiere al psicoanálisis freudiano $y$ al marxismo-leninismo. Asimismo, el artículo muestra problemas de fondo que no se pueden obviar.
El artículo de Martínez inicia con la reflexión sobre el materialismo dialéctico y la subjetividad. Pero, ya aquí, el expresa una incomprensión del marxismo ${ }^{1}$. Él define la subjetividad, entendida materialistamente, como un proceso de "transformación y apropiación de la realidad en tanto mundo natural y entorno social, estando definida la condición humana por su cualidad de ser activa y creativa" (2007: 85-86). Es decir, según él mismo indica, para este sujeto el "mundo es algo para sí" (2007: 85). La subjetividad materialista sería entonces proyecto, en tanto el mundo se subjetiviza en el proceso práxico.

Así, para él, la praxis es un proceso de autoperpetuación consciente de la especie ${ }^{2}$. Luego, la conciencia siempre es un producto social que está en estrecha relación con la posesión o no-posesión de los medios de producción, en tanto reflejo de una formación social que impone sus intereses hegemónicos, inevitable y universalmente, sobre el todo social: "el sujeto es un producto de la historia que le determina y de la cual es también artífice" (Martínez, 2007: 86). Dentro de este marco, Martínez plantea la alienación como un concepto ligado únicamente a la separación entre producto y productor (2007: 86). Mas, el concepto de alienación tiene dos acepciones dentro del ideario marxista: Entfremdung (distanciamiento, extrañamiento) y Entäusserung (desposeimiento, alienación) ${ }^{3}$. Entäusserung refiere al proceso en el cual el trabajo se hace ajeno al hombre, en cuanto se establece la cesión (Veräusserung), o sea, la praxis de desposeimiento, en donde el obrero depone su fuerza de trabajo como mercancía ${ }^{4}$

1 Marxismo que hasta estas alturas se presenta como si fuera el marxismo en general y no su versión leninista.

2 "En la transformación del mundo la humanidad emerge como tal, autoperpetuándose como especie consciente" (Martínez, 2007: 86) Destacado mío.

3 Marx acostumbraba a usar ambos términos para referirse al concepto de alienación (cfr.: Marx, 1977: 199).

$4 \quad$ Marx establece que en este sentido el trabajo aparece "como la pérdida de realización de los trabajadores" (1977: 68). Traducción mía. Es interesante que ya esta noción marxiana de pérdida 
(Israel, 1977: 78-79). Más o menos, esta es la idea que tiene Martínez en mente cuando habla de alienación.

Por otra parte, el concepto de Entfremdung se relaciona con las condiciones de objetivación que niegan la libertad del hombre $^{5}$. Es decir, la alienación tiene un componente existenciario que es producto del contexto que impide al ser humano realizarse libremente. Por ende, si bien la alienación se fundamenta en la separación entre producto y productor, también es cierto que tal separación trae consecuencias a nivel psíquico. De alguna manera, la separación obrero-producto es equivalente al proceso de separación entre un padre o madre $y$ un hijo. Ontológicamente, tanto el producto, como el hijo son una extensión del ser o seres de donde ellos adquieren existencia.

Desde una perspectiva psíquica, afirma Martínez, el sujeto del marxismo es "la acciónasimilación de contexto social y de las formas de actividad históricamente estructuradas" (2007: 87). Esta definición igualmente implica un error grave de interpretación del sujeto del materialismo dialéctico, por cuanto Martínez cierra contundentemente este sujeto en el contexto social, dado en alguna determinada actividad estructurada en algún determinado momento histórico. El problema aquí es que esta noción es demasiado positiva y positivista como para ser correcta. Martínez niega la dialéctica entre sujeto $y$ objeto, ya que, la realidad es asumida como un ente pasivo, dúctil y maleable ante la acciónasimilación del ser humano. Luego, el para-sí ${ }^{6}$ se asume como un proceso unidireccional que parece producto de la interrogación de una realidad que, en tal movimiento, nos devuelve su "verdad", con el único fin de que podamos servirnos de ella. Martínez olvida que en el mismo

implica consecuencias de tipo psíquico, en tanto la imposibilidad de realización tiene consecuencias sobre la autoestima.

"La apropiación aparece como extrañamiento (Entfremdung), como alienación (Entäusserung); y la alienación aparece como apropiación" (Marx, 1977: 79). Traducción y paréntesis míos.

6 Más adelante retomaremos críticamente la noción de para-sí en el pensamiento de Martínez. proceso el ser humano se transforma y deviene exterioridad en lo producido, y que luego esto que fue producido cambiará necesariamente el en-sí del sujeto.

El aparato cognitivo del ser humano se altera en el proceso de acción-asimilación ${ }^{7}$ (la praxis) en tanto la técnica, la ciencia y la tecnología cambian, maduran y profundizan los procesos de abstracción. Procesos que no son más que la cada vez más detallada división del trabajo.

Así, en tanto la división del trabajo y el "mejoramiento" del aparato cognitivo continúan, el proceso negativo se hace cada vez más claro y menos mesiánico. Es decir, cada vez tenemos el conocimiento y el desarrollo tecnológico que nos posibilitan pensar-construir un mundo más solidario y menos sometido al mundo laboral (Arbeitswelt). La utopía aparece ya no como la quimera evasiva de tantas ilusiones utópicas ${ }^{8}$, sino como el horizonte de unidad ontológica entre Ser y Deber-ser. Realidad y posibilidad se funden en la materialidad de las categorías de lo lógico y lo histórico. Lo particular y lo general se funden en la continuidad dialéctica de la Historia (Geschichte) y en el devenir filo-ontogenético de la humanidad.

Según Martínez, el sujeto psicoanalítico de Freud, por otra parte, está unido al individuo, con lo cual se separa de la psicología marxista que se asienta en lo social. En Freud, la libido no se establece como el motor de la historia, sino en tanto fuerza que se organiza alrededor de una realidad ahistórica llamada familia, en cuyo seno se producen procesos psíquicos (filo-ontogenéticamente hablando) exempli gratia: la fase edípica (2007: 87-88). Para Freud, entonces, el sujeto es un individuo que es "el resultado de tendencias y experiencias psíquicas primigenias mediadas — hasta cierto punto- por las restricciones civilizatorias" (Martínez, 2007: 90).

$7 \quad$ Retomaremos esto posteriormente.

8 Raúl Vidales nos ofrece la distinción entre "realidades utópicas" e "ilusiones utópicas". Las realidades utópicas refieren a lo que todavía no es, pero puede devenir: es la posibilidad presente en la realidad. Al contrario, la ilusión utópica refiere a lo que no puede ser, es decir, lo no posible (1991: 25). 
El sujeto, que Martínez achaca al psicoanálisis, es un sujeto tal que es definido por vía no-positiva. Este sujeto, ateniéndonos a lo que Martínez expresa, es un mar de represiones, que funcionan en un ambiente cerrado que no permite ir más allá de lo que podría permitir el ahistoricismo de esta definición, es decir, la nada. En el sujeto, por ende, no habría nada positivo (en sentido epistemológico). Todo en él sería la propia anulación del sí mismo, ya que, todos aquellos comportamientos observables $y$ conscientes del sujeto (es decir, todo lo positivo) se resumen en un engaño de fuerzas misteriosas. Con esto estaría negando la función catártica de la misma terapia psicoanalítica. Al menos que él esté pensando que el proceso terapéutico es un juego esquizofrénico que solo busca crear un receptor imaginario que legitime y justifique el conjunto de síntomas, con la idea de establecer una normalidad de carácter identitario.

Todo esto es manejado por Martínez con el fin de establecer una contraposición entre el sujeto del psicoanálisis y el del marxismo.

De esta contraposición entre el sujeto del marxismo y el del psicoanálisis freudiano, Martínez deriva que existe una incompatibilidad entre ambos paradigmas teóricos, en tanto la noción de cultura freudiana y la noción de sociedad marxista no se corresponden. La noción de cultura en Freud responde a un proceso de sublimación entendido como pacto mítico, mientras que el concepto marxista de sociedad se enfrasca en la reproducción material de la especie (Martínez, 2007: 90).

Todo lo anterior tiene un fin en el pensamiento de Martínez, o sea, afirmar que "Quizá ha llegado la hora de renunciar a afanes omnicomprensivos y omniexplicativos que den cuenta de la totalidad del acontecer humano, $y$ mirar con absoluto respeto otros desarrollos teoréticos cuyas discursividades vayan más allá del propio, reconociendo implícitamente nuestras limitaciones" (Martínez, 2007: 92).

\section{CRÍTICA AL PLANTEAMIENTO MARTINEZIANO}

Martínez comete varios errores en la interpretación tanto del marxismo, como del psicoanálisis. Su afán de denigrar las aproximaciones omnicomprensivas y omniexplicativas, lo lleva a reducir la antropología marxista y a deshistorizar el psicoanálisis.

Cuando Martínez establece un sujeto marxista ligado al para sí, está reduciendo tal sujeto a su pura exterioridad, debido a dos motivos:

$\diamond$ El sujeto efectivamente es un para sí, es decir, se manifiesta en la continuidad como proyecto a través del devenir histórico y de la angustia existencial ${ }^{9}$. Sin embargo, el devenir proyecto no es un simple acto accidental, sino que tal cualidad proviene de un Ser tal que siendo en sí, puede (auto) definirse como movimiento consciente en el acto de elección, aunque no siempre consciente de sus inconscientes razones ${ }^{10}$. En otras palabras, sin Ser-en-sí es imposible devenir para sí. Como en el caso de una recta, que es la suma de puntos que la componen, el en sí es cada uno de esos puntos que componen la continuidad que llamamos precisamente "recta". Así, como no podemos pensar la recta sin puntos, tampoco podemos pensar un Ser-para-sí sin en sí.

$\diamond$ Martínez, al reducir el Ser del sujeto a un para sí, lo encasilla en lo positivo, es decir, lo define en su manifestación observable ${ }^{11}$. Martínez, contradictoriamente, cierra el Ser del sujeto en un en-sí, pero este en-sí es simplemente un reflejo ideológico que pretende anular la negatividad del Ser. El

Sartre (1989) explica perfectamente las implicaciones existenciales que enfrenta el sujeto en su seren-proyecto. O sea, con Sartre podemos contraponer a las nociones del determinismo histórico, la responsabilidad del sujeto. Profundizaremos en esto posteriormente.

10 Estoy pensando en los procesos ideológico-alienantes que envuelven al sujeto. Volveremos sobre esto.

11 Según Martínez, "Para el marxismo la característica fundamental del funcionamiento psíquico es la acción-asimilación del contexto social y de las formas de actividad históricamente estructuradas" (2007: 87). 
para-sí martineziano es el en-sí del agente histórico que, siguiendo a Alfaro, se mueve entre lo racional-teleológico y lo racionalreproductivo. El sujeto que Martínez achaca al marxismo es un no-sujeto, es el individuo que "se halla en una realidad, en la cual las condiciones objetivas para la superación de lo establecido no están dadas" (Alfaro, 2007: 12). Dicho más simplemente, Martínez confunde la agencialidad histórica con la subjetividad histórica. Así, "El sujeto histórico es el producto de un proceso colectivo y coyuntural, en el cual el modo de producción y la formación social respectiva están en una crisis sistémica que devendrá en su superación" (Alfaro, 2007: 12). La subjetividad histórica no es una esencia inmutable $y$ omnipresente en el tiempoespacio, es el producto de un proceso histórico de rompimiento. Igualmente, la agencialidad histórica es la antítesis de tal sujeto, por tanto es un producto contingente de la necesidad histórica. El agente se amarra a la cotidianidad, el sujeto crea la vida cotidiana (entendido esto en términos lefebvrianos) ${ }^{12}$. El agente vive el orden cercano del establishment. El sujeto va tras el orden lejano, la consecución de la utopía. Uno niega al otro, ley de la negación de la negación.

Dentro de la perspectiva de Martínez, el pretendido sujeto marxista es la expresión del determinismo histórico, ya que, "es un producto de la historia que le determina y de la cual es también artífice" (Martínez, 2007: 86) ${ }^{13}$.

12 Lefebvre establece la oposición dialéctica entre cotidianidad $y$ vida cotidiana. La cotidianidad es esencia pura, que separa forma y contenido, en tanto producto de las relaciones de producción actuales (Lefebvre, 1972: 218-222). La vida cotidiana es el centro real de la praxis, a partir del cual es pertinente realizar lo posible (Lefebvre, 1972: 44 y 24$)$.

13 Esta idea de que el sujeto es determinante de la historia $y$ determinado por ella no se sostiene después de haber explicado las nociones de agente histórico y de sujeto histórico. Esto por cuanto si asignáramos un valor positivo o negativo al sujeto según su calidad de actividad con respecto a la historia, entonces tendríamos, por ejemplo, el valor de 1 (uno) cuando su acción es determinante
No obstante, como vimos anteriormente, este sujeto marxista definido por Martínez es un nosujeto; luego, es un agente histórico y por ende, reproduce crítica o acríticamente lo establecido, en un contexto donde las condiciones de cambio social no están dadas. Por consiguiente, Martínez hace del sujeto histórico marxista una categoría ideologizada que anula la dialéctica entre el agente y sujeto históricos. Esto es determinismo histórico.

El sujeto del psicoanálisis es definido dentro de una perspectiva freudista ${ }^{14}$. 0 sea, el sujeto dentro de este paradigma es un conglomerado de represiones e interiorizaciones que el individuo introyecta sobre la fase edípica (cfr.: Martínez, 2007: 90). En este sentido, el superyó en tanto sublimación de la energía psíquica es lo que permite acceder al ser-sujeto. Este ser-sujeto psíquico está determinado por la dinámica de la libido, la cual, lejos de referir a los procesos socio-históricos, refiere a la lucha entre catexias y contracatexias, las cuales son la expresión de un Ello que impulsa a lo instintivo y de las exigencias civilizatorias, de las que habla Martínez.

Este ser-sujeto psíquico es él mismo en todo tiempo y lugar, en tanto producto de un sistema ahistórico denominado familia. Así, nos dice Martínez que "para Freud la familia aparece como una realidad ahistórica y socialmente descontextuada $y$ aislada; es una realidad $y$ un fin en sí mismo" (2007: 88). Por ende, siguiendo la línea de Martínez, de una realidad ahistórica (la

en el proceso histórico y de -1 (menos uno) cuando él fuera determinado por la historia. Como según Martínez, estos dos procesos se dan simultáneamente, entonces el valor del sujeto sería nulo, lo cual nos recuerda el sujeto tachado lacaniano (\$). Parece existir la clara tendencia en Martínez por eliminar la idea de sujeto, en tanto ente operante de la realidad. Esto está relacionado con la oculta posición posmoderna que más adelante discutiremos.

Con el término "freudista" hacemos referencia a la idea del Freudismo, o sea, la equivocada noción de reducir la realidad psíquica al marco teórico desarrollado por Freud. Esto se marca gráficamente en el sufijo "-ismo" que indica la preponderancia de algo. Atendiendo a este sentido, Marx no era marxista. 
familia) solo se puede derivar un sujeto también desligado de la Historia (Geschichte), la cual, por consiguiente, se reduce a la historia (story) del sujeto psíquico del psicoanálisis.

El sujeto del psicoanálisis no tiene nada que ver con la Historia, que es un proceso colectivo, sino que se cierra sobre el sujeto biológico, sobre el individuo aislado, sobre la mónada.

Martínez confunde la ahistoricidad del aparato conceptual de Freud, haciéndola pasar del cuerpo conceptual a la realidad. Esto con el claro fin de establecer una diferencia insuperable entre el sujeto del psicoanálisis y el del marxismo, ya que, según Martínez, "A diferencia de Freud el sujeto en Marx es social" (2007: 89).

Esta contundente separación que Martínez establece, sin embargo, no es gratuita. Su oculta pretensión la encontramos en la siguiente cita: "Quizá ha llegado la hora de renunciar a afanes omnicomprensivos $y$ omniexplicativos que den cuenta de la totalidad del acontecer humano" (Martínez, 2007: 92). Aquí su posición es claramente posmoderna. Su afán de renunciar a la comprensión de la totalidad, nos recuerda el ensañamiento que la posmodernidad tiene en contra de los denominados "metarrelatos". Martínez mismo señala que debemos "mirar con absoluto respeto otros desarrollos teoréticos cuyas discursividades vayan más allá del propio, reconociendo implícitamente nuestras limitaciones" (2007: 92). O sea, debemos operar algún tipo de descentramiento de tipo derridiano que nos salve del carácter totalizante de algunas teorías de la Modernidad (marxismo y psicoanálisis, por ejemplo) y también, debemos aprender enfoques anclados en categorías particularistas que nos recuerden el relativismo propio de nuestros cuerpos teóricos.

Por esta oculta posición posmoderna, es que se dificulta comprender el manejo que Martínez hace tanto del marxismo, como del psicoanálisis. Como vimos se reduce el sujeto marxista a un puro para-sí. Luego, se centra en las características ahistóricas del psicoanálisis para cerrar este paradigma en lo monádico.

Hoy es ya absurdo seguir manteniendo un discurso posmoderno, cuando el discurso económico-neoclásico de la globalización ha caído en manos de una crisis financiera, que ha obligado a la intervención estatal negando el principio de preponderancia de las leyes del mercado. La posmodernidad era la ideología de la globalización. Luego, sin globalización y libre mercado no hay posmodernidad ${ }^{15}$. La cleptocracia ${ }^{16}$ globalizante y posmoderna mostró en su agonía intervencionista, su rostro más ambicioso y más deshumanizado.

Lo pertinente, dentro de este contexto, es repensar dialécticamente la relación marxismopsicoanálisis, aunque esto suponga precisar de nuevo el objeto del psicoanálisis.

\section{MARXISMO Y PSICOANÁLISIS: ¿UNA REFORMA EPISTEMOLÓGICA?}

Freud vivió dentro de una sociedad que reprimía la sexualidad. De ahí que el problema fundamental giraba alrededor de la neurosis que tal represión engendraba. Pero, el tiempo transcurrió y las sociedades actuales impulsan a gozar el síntoma ${ }^{17}$, a la manera en que Marcuse plantea su versión hedonista de la sociedad ${ }^{18}$. Entonces, es evidente que es preciso releer a Freud.

El psicoanálisis freudiano siempre tuvo un aire de ahistoricismo, anclado en la misma noción del inconsciente. Martínez lo define como "una especie de inmovilismo histórico" (2007: 90). Este inmovilismo histórico crea en

Eduardo Grüner (s.f.e.) indica que existe una estrecha relación entre el pensamiento posmoderno y la globalización, ya que, no es producto del azar el que ambos términos hayan aparecido simultáneamente $y$ de hecho, el que los dos se inserten dentro de la crisis del Estado benefactor (o Estado de bienestar) y dentro del contexto del derrumbe de los (mal llamados) socialismos reales.

El término es de Mansilla (2006: 118).

Estoy pensando en el texto de Žižek llamado ;Goza tu síntoma!

18 Marcuse exacerba el rol del Eros, debido a que, para él, esta es la contra-fuerza que se opone a la energía que tiene carácter agresivo-destructivo (1972: 9). El Eros es la fuerza que tiende a la unión (sexual), es placer. 
consecuencia un determinismo histórico ${ }^{19}$, en tanto la personalidad se estructura por un juego entre las energías pulsionales y los imperativos sociales propios de la introyección de la normativa social. El instinto sexual lucha contra la moralidad que le pone límites. Este enfoque refleja un sistema cerrado entre lo biológico y lo social. La libido es quien lleva la voz cantante en el concierto de la elaboración de la personalidad. Así, el determinismo no es solo histórico, sino también biológico.

Con Lacan, recordemos, se pone en duda totalmente la idea del determinismo social, en cuanto el sujeto de la simbolización es un sujeto incompleto, en tanto le falta aquello que la suplementariedad de lo real $y$ de lo imaginario le suple. Lo suplementario acaba con el determinismo tanto histórico, como social. Lacan tiene razón cuando relativiza el papel de lo simbólico (ligado a la fase edípica de Freud). Pero, él comete un error cuando hace de lo simbólico una estructura represiva que tacha el sujeto. Esto es aún más claro en Althusser (1987: 86), quien nos dice que en tanto el sujeto es producto de los aparatos ideológicos del Estado (AIE), entonces el sujeto es producto de la interpelación ideológica. Luego, el sujeto siempre está sujetado a la ideología. No hay escape.

El fatalismo es claro, así como la visión antihumanista. El sujeto solo es capaz entonces de discursar, ya que, la praxis es la simple reproducción del esquema represivo que conformó el sujeto. Por eso, Lacan nos dice que el inconsciente está estructurado como lengua$\mathrm{je}^{20}$. Es un simple juego de significantes, en donde, siguiendo a Derrida, no hay historia, ni estructura $^{21}$. De este modo, reaparece el ahistoricismo.

Lo dado no se puede alterar, está inmóvil.

20

El inconsciente es una "cadena de significantes que en alguna parte se repite e insiste para interferir en los cortes que ofrece el discurso efectivo y la cogitación que él informa” (Lacan, 1972: 46).

De hecho, estoy interpretando este juego de significantes como una expresión de la différence, ya que, esta "no pertenece simplemente ni a la historia, ni a la estructura" (Derrida, 1967: 47). Traducción mía.
Entonces, es necesario aceptar con Lacan que la asimilación de la normativa social no es producto de un determinismo social, pero alejándonos del mismo Lacan, cuando él plantea la reducción de lo inconsciente a un juego semiótico. Es preciso retomar la praxis como criterio material, es decir, debemos retomar los procesos de socialización tanto en su función filogenética, como en la ontogenética. Pero, ¿qué implicaciones traerá esto?

En el pasado, la Escuela de Frankfurt intentó una crítica de la civilización basada en un análisis psicoanalítico, que permitiera visualizar cómo se reprimían los instintos básicos dentro de la sociedad capitalista. Ejemplo claro de esta propuesta es Marcuse, quien al igual que Lacan, privilegia el principio de placer sobre el de realidad. Esto por cuanto el principio de realidad (la sociedad industrial en Marcuse y lo simbólico en Lacan) aparece como elemento "alienante" que somete al individuo a los vaivenes de la Ley.

Recordemos al personaje central de $L a$ Metamorfosis de Kafka, Gregorio Samsa, quien es representado metafóricamente como un ser animalizado, en tanto manifestación de un sistema que lo ata al principio de rendimiento ${ }^{22}$ propio de un trabajo alienante. Gregorio vive para la empresa. Su vida es viajar-venderdormir. El principio de realidad se define en relación con lo comportamental y positivo (lo dado) lo cual impide visualizar otros espacios de construcción utópica.

Así, Marcuse se refugia en el principio de placer como un medio para acceder a los instintos básicos, en tanto elemento socio-catártico. No obstante, el placer es muerte, ya que, el placer es la satisfacción de una carencia y el estado par excellence sin carencia es la muerte. Lo único que logra afirmar Marcuse es el hedonismo, que es propio del capitalismo consumista, en donde es necesario consumir a cada instante. El deseo insatisfecho ${ }^{23}$ es la lógica del hedonismo y del

22 Confróntese: (Blérald, 1980: 847).

23 Es el "círculo vicioso de un deseo, cuya aparente satisfacción solo amplia el hueco (gap) de su propia insatisfacción" (Žižek, 1990: 60). Traducción mía. 
capitalismo actual. La muerte es el signo de este período capitalista.

De hecho, la solución marcusiana al problema de complementar marxismo y psicoanálisis no llega a buen término. El placer lejos de ser un elemento de cambio social aparece como el dulce grillete de las sociedades globalizadas e industriales. Sin embargo, nos da la clave para resolver el problema.

La siguiente anécdota nos servirá para ejemplificar. En mi pueblo, San Ramón, tuve la oportunidad de asistir a un psicólogo en el levantamiento de información (aplicando una entrevista) a un grupo de trabajadores de una empresa local.

Al entrevistar a un repartidor, él me preguntó que cuál era la idea de aplicar tales entrevistas al personal. Yo le dije que la idea era recolectar información para crear algunos tipos de perfiles profesiográficos, con el fin de mejorar los mecanismos de contratación (supuestamente). Él respondió entonces que eso era muy bueno, ya que, las últimas contrataciones habían sido algo fallidas. Además, expresó que era necesario evitar contratar gente problemática. ¿Gente problemática? Pregunté yo. Sí, por ejemplo, sindicalistas, dijo él. ¿Cuál es el problema con los sindicalistas (insistí yo)? A lo cual respondió el trabajador: "Ellos traen problemas. Vienen y reclaman por los horarios u otras cosas. Nos dicen que nos están haciendo trabajar de más".

Al final del día, después de estar recolectando información durante horas, finalmente terminamos. Me reuní con mi amigo psicólogo, quien había hecho la otra mitad de las entrevistas, y le dije: "Esto es un infierno". Él me respondió sin titubear: "Sí, efectivamente". Los trabajadores eran obligados a trabajar regularmente sin respetar los horarios de alimentación. Además, en algunos casos estaban entregándole 20 horas por mes de trabajo gratuito al dueño y gerente de la empresa. Los horarios de la empresa no le permitían a ningún trabajador realizar otra actividad fuera de su "obligación laboral". También, tenían que ser proactivos ${ }^{24}$.

Dícese de la actitud que el trabajador desarrolla con el fin de autoexplotarse, creyendo que es mejor persona al cumplir con los lineamientos de alguna ideal ética laboral. A los administradores no les gustará mi definición de proactividad.
Si recordamos al trabajador que no quería a los sindicalistas, podemos iniciar nuestro análisis. Evidentemente, este trabajador sufría la explotación por parte de sus jefes. Él trabajaba 20 horas más al mes por nada. El sindicalista (que creo se proyectaba en otro trabajador que abiertamente se quejó del maltrato laboral) era el elemento que rompía la fantasía de la gran familia empresarial ${ }^{25}$, ya que, rompía el proceso de negación (Verneinung) que le "permitía" sobrellevar la mala situación laboral. De ahí que el rencor que tenía hacia sus jefes lo desplazaba hacia esta figura abstracta llamada sindicalista, quien condensaba al compañero que reclamaba $y$ al jefe mismo.

Este trabajador se amarraba a una ética laboral, que iguala ser un buen trabajador, con la noción de ser una buena persona. Cualquier cosa que lo aleje de esta fantasía aparece como algo reprochable.

La única manera, además, de que nuestro trabajador se afiance a esta idealización ética, es que su autoestima esté (casi) totalmente destruida. Cognitivamente, él no puede evitar percibir la situación de abuso a la que es sometido por sus jefes. Sin embargo, la niega. El trabajo deviene su espacio de autocastigo. En su retorcido inconsciente, él merece ser castigado. Él debe ser un buen trabajador, un buen proveedor, un buen padre, etc. Las ganancias secundarias le afirman su enfermizo comportamiento. Alguien le dirá: "iQué buen trabajador o marido o padre eres!”. Asimismo, él podrá consumir compulsivamente. Comprará su carro, con lo cual llenará la noción burguesa de éxito social y atraerá mujeres que también respondan a la dinámica socio-ideológica del consumismo, con el fin de obtener sexo. El placer funciona como cárcel.

El trabajador está alienado y se aliena a sí mismo porque no tiene autoestima. Durante el proceso edípico, su autoestima empezó a destrozarse: un hombre es así como papá, sin emociones. La castración simbólica está en acción. En la socialización secundaria se le asignaron

El grupo de trabajadores había sido llevado a algún tipo de convivencia que incluía a los dueños, guiados por una psicóloga laboral. 
autoritariamente roles que aceptó sin cuestionar y ahora debe cumplirlos "placenteramente".

El concepto de autoestima nos permite conjugar el concepto de superyó con los procesos materiales que subyacen a la socialización. La manera en que se conforma la conciencia moral depende de las necesidades inherentes al proceso que se desarrolla en la respectiva formación social y en el correspondiente modo de producción. Así, dentro de un capitalismo con una organización fordista, es preciso socializar individuos con una estructura de personalidad básicamente obsesivo-compulsiva, los cuales puedan gustar del trabajo rutinario, con poco contacto social, etc. En cambio, si estamos dentro de un marco consumista es mejor socializar con fines a estructurar una personalidad histérica, en donde el deseo esté siempre insatisfecho para que así consuma y consuma ${ }^{26}$.

Los procesos de socialización dependen de lo que Althusser llamaba los aparatos ideológicos del Estado (AIE): la iglesia, la escuela, los medios de comunicación, etc.; que se empeñan en realizar la tarea que necesitan sus dueños burgueses. O sea, los AIE inculcan culpas y miedos, que día con día destruyen la autoestima de la masa trabajadora.

Con el análisis de los procesos de conformación de la autoestima, podemos encontrar cuáles son los puntos manipulados, para así corregirlos y construir una nueva y mejor sociedad, con individuos más autorrealizados y con

Mansilla nos ejemplifica este mismo fenómeno: "En ciertos períodos históricos, como la fase del capitalismo clásico de la segunda mitad del siglo XIX, la estructura familiar contribuyó a formar individualidades fuertes, orientadas según el paradigma de un padre económicamente autónomo, políticamente liberal, moralmente estable que irradiaba seguridad y confianza" (2006: 115). Aunque le faltó machista y rígido, Mansilla describe la estructura anal de la obsesividad compulsiva, muy acorde a la necesidad de proyectar dominio y control, dentro de un proceso capitalista que necesitaba un dominio autoritario sobre los procesos de producción monótonos y que le permitiera evadir la culpa de la explotación, mediante un superyó rígido e insertado dentro de una visión ética desmaterializada. la mejor autoestima posible. Catarsis ${ }^{27}$ y utopía coinciden en este punto. Ambos son la expresión negativa de la superación (Aufhebung) dialéctica. La catarsis final es la construcción de una sociedad no-capitalista ${ }^{28}$.

\section{CONCLUSIÓN}

Efectivamente, el concepto de autoestima permite amalgamar los dos paradigmas teóricos. El concepto de autoestima sirve de síntesis entre el sujeto del psicoanálisis y el del marxismo, como un medio de aprehender los procesos psico-sociales que se establecen al interior de nuestras sociedades capitalistas, que han llevado al ser humano a un proceso de alienación que lo hacen extraño a sí mismo y a la naturaleza.

El olvido a nivel teórico de los procesos filo y ontogenéticos ha llevado a plantear una posmodernidad que aleja al ser humano de lo que le distingue, su razón. Tanto el marxismo, como el psicoanálisis persiguen un ser humano más consciente, capaz de entender los procesos de autoconformación de su propia autoestima, así como los de su sociedad. Todo esto dentro de la visión humanista que heredamos de la Modernidad y que la derecha capitalista ha pervertido.

Debemos recuperar en la conjunción entre marxismo y psicoanálisis la elaborada y hoy olvidada necesidad psico-biológica de la pereza. Recordar que el trabajo por sí solo no dignifica a nadie. Un ser humano sometido a la necesidad del rendimiento laboral, es siempre un ser insatisfecho y psicológicamente aplastado. El gran desarrollo tecnológico, con su

$27 \quad$ La misma idea de catarsis elimina cualquier rasgo de determinismo social, ahistoricismo o de fatalismo. La catarsis implica que puede construirse un ser humano mejor. Los resultados terapéuticos lo atestiguan.

O como diría Mansilla una sociedad razonable definida como donde sus "miembros experimentan un reconocimiento mutuo, sentimiento que abarca, a su vez, comprensión, autoconfianza, amor, estima, o resumiendo solidaridad" (2006: 114). Mejor resumen nos da la palabra autoestima. 
correlativo aumento en la jornada laboral, no es para aumentar la ganancia del capitalista. La tecnología es para reducir el tiempo que se necesita para producir los medios de subsistencia y así, disponer de más tiempo para el compartir.

El marxismo nos ofrece el andamiaje socio-político y conceptual, el psicoanálisis nos pone en la línea de una ingeniería social liberadora. Dice un dicho popular que "el chancho es como lo crían". Entonces, eduquémonos libres, solidarios, sin ambición, con responsabilidad ecológica y principalmente, con techo, alimentación, vestido, educación y diversión no-consumista para todos.

\section{BIBLIOGRAFÍA CONSULTADA}

Alfaro Vargas, Roy. "Antropologías literarias: prolegómenos a la praxis textual". Praxis: Revista de la Escuela de Filosofía. Universidad Nacional 59, enero-junio. 2007: 7-17.

Althusser, Louis. Ideología y aparatos ideológicos del Estado. Sétima reimpresión. México. Ediciones Quinto Sol, 1987: 86.

Berger, Peter y Luckmann, Thomas. La construcción social de la realidad. Traducción: Silvia Zuleta. Buenos Aires: Amorrortu Editores, 1968: 236.

Blérald, Philippe-Alain. "Lire Marcuse: pour une théorie critique de la société industrielle". Les Temps Modernes 412, novembre, 36e année. 1980: 842-863.

Derrida, Jacques. L'écriture et la différance. Paris. Éditions du Seuil, 1967: 440.

Derrida, Jacques. De la gramatología. Buenos Aires. Siglo Veintiuno Editores, 1971: 397.

Dierckxsens, Wim. Del neoliberalismo al poscapitalismo. San José, Costa Rica. DEI, 2000: 184.
Freud, Sigmund. La interpretación de los sueños (2). $8^{\mathrm{a}}$ edición. Madrid. Alianza Editorial, 1975: 288.

Freud, Sigmund. La interpretación de los sueños (3). $8^{\text {a }}$ edición. Madrid. Alianza Editorial, 1976: 256.

Freud, Sigmund. La interpretación de los sueños (1). $11^{\mathrm{a}}$ edición. Traducción: Luis López Ballesteros. Madrid. Alianza Editorial, 1978: 240.

Freud, Sigmund. Psychopathology of Everyday Life. Translation by A. A. Brill. Eleventh printing. New York, USA. Mentor Books, 1980: 160 .

Grüner, Eduardo. s.f.e. El fin de la posmodernidad. (En línea). En: <http:// www.pais.global.com.ar/modules.php?o $\mathrm{p}=$ modloud $\&$ name $=$ new $\&$ file $=$ article $\&$ $\operatorname{sid}=2476 \&$ mode $=$ thread $\&$ order $=0 \&$ th old $=0>$ [recuperado el 16 de agosto del 2005].

Hall, Calvin. Compendio de psicología freudiana. $5^{\text {a }}$ edición. Traducción: Marta Mercader. Buenos Aires. Paidós, 1974:144.

Hegel, G. W. Lógica. $2^{\text {a }}$ edición. Traducción: Antonio Zozaya. Madrid. Editorial Ricardo Aguilera, 1973: 374.

Hinkelammert, Franz J. Crítica de la razón utópica. $3^{\text {a }}$ edición. San José, Costa Rica. DEI, 2000: 275.

Israel, Joachim. Teoría de la alienación. Traducción: José F. Ivars y Pilar Esterlich. Barcelona. Ediciones Península, 1977: 472.

Jameson, Fredric. El posmodernismo o la lógica cultural del capitalismo avanzado. Traducción: Pardo Torio. Buenos Aires. Paidós, 1992: 128. 
Jameson, Fredric. Teoría de la posmodernidad. $2^{a}$ edición. Traducción: Celia Montolío y Ramón del Castillo. Madrid. Editorial Trotta, 1998: 334.

Kopnin, P. V. Lógica dialéctica. Traducción: Lidya Kuper. México. Grijalbo, 1966: 564.

Lacan, Jacques. Las formaciones del inconsciente. Buenos Aires. Ediciones Nueva Visión, 1972: 176.

Lacan, Jacques. Escritos 2. Traducción: Tomás Segovia. México. Siglo Veintiuno Editores, 1975: 432.

Lacan, Jacques. Escritos 1. Traducción: Tomás Segovia. Buenos Aires. Argentina. Siglo XXI Editores, 2005: 512.

Lefebvre, Henri. La vida cotidiana en el mundo moderno. Traducción: Alberto Escudero. Madrid. Alianza Editorial, 1972: 256.

Leite Lopes, José Sergio. "Subjetividade e linguagem do trabalho". Revista Latinoamericana de Estudios del Trabajo 5. Año 3. 1997: 40-52.

Mansilla, HCF. "El mundo de ayer, la comprensión de nuestros límites y la depravación de las élites". Revista de Ciencias Sociales 113-114. Universidad de Costa Rica, 2006: 113-121.

Marcuse, Herbert. Eros y civilización: una investigación filosófica sobre Freud. $5^{\mathrm{a}}$ edición. Traducción: Juan García. México. Editorial Joaquín Mortiz, 1970: 288.

Marcuse, Herbert. El hombre unidimensional. $9^{a}$ edición. Traducción: Antonio Elorza. México. Seix Barral, 1972: 296.
Martínez, Manuel. "Psicoanálisis y marxismo: una imposibilidad paradigmática". Revista de Ciencias Sociales 115. Universidad de Costa Rica, 2007: 85-93.

Marx, Karl. Economic and Philosophic Manuscripts of 1844. Fifth revised edition. URSS. Progress Publishers, 1977: 234.

Marx, K. and Engels, F. The German Ideology. Third revised edition. URSS. Progress Publishers, 1976: 718.

Sartre, Jean Paul. "Existentialism is a Humanism". Tomado de: Kaufman Walter (ed.). Existentialism from Dostoyevsky to Sartre. Translated by: Philip Mairet. 1989. (On line). En: <http://www.marxists.org/reference/ archive/sartre/works/exist/sartre.htm> [Recuperado el 19 de setiembre de 2008].

Stiglitz, Joseph. El malestar en la globalización. $6^{a}$ reimpresión ( $1^{a}$ edición). Traducción: Carlos Rodríguez Braun. Buenos Aires. Taurus, 2002: 352.

Vidales, Raúl. Utopía y liberación: el amanecer del indio. $2^{\text {a }}$ edición. San José, Costa Rica. DEI, 1991: 208.

Žižek, Slavoj. "Eastern Europe's Republic Gilead". New Left Review 183, septemberoctober. 1990: 50-62.

Žižek, Slavoj. ;Goza tu síntoma! Traducción: Horacio Pons. Buenos Aires. Ediciones Nueva Visión, 1994: 240. 
